\title{
OÚRICURI
}

\section{A BIOCIÊNCIA DOS AGROTÓXICOS E SEU IMPACTO NA SAÚDE}

\author{
Astrid Merino SILVERIO'*; Patrícia Barros PINHEIRO²
}

\begin{abstract}
${ }^{1}$ Médica em Atenção de Saúde da Família na Unidade Básica de Saúde Josefa Bispo de Almeida. Rua Cinquenta e seis, 21, João de Deus. CEP: 56.316-566. Petrolina-PE. *Autor Correspondente. E-mail: astridmerino2014@yahoo.com.br;

2Docente da Universidade do Estado da Bahia, Departamento de Educação - DEDC, Campus VIII. Rua do Bom Conselho, 179, Alves de Souza. CEP: 48.608-230. Paulo Afonso-BA. E-mail: ppinheiro@uneb.br Recebido: 30.06.19 Aceito: 30.05.20 http://doi.org/10.29327/ouricuri.9.2-9
\end{abstract}

\begin{abstract}
Resumo: O presente estudo trata-se de um enfoque biomolecular e celular dos danos a saúde produzidos pelos agrotóxicos na Biociência, como ciência interdisciplinar, que estuda os seres vivos, sua evolução, o ambiente em que vivem, o modo como se relacionam, etc. Realizou-se uma investigação de caráter cognoscitivo do estado da arte, em artigos publicados de 1979 a 2019. Desde os anos 60 são estudados os impactos na saúde causados pelos agrotóxicos e são fornecidas bulas a populações, com orientações das formas mais adequadas de aplicação de medidas de proteção a serem cumpridas pelos agricultores, para que esses agravos a saúde tenham um menor impacto, no estado de bem-estar deles e dos consumidores. Longe de serem cumpridos esses protocolos de prevenção, famílias inteiras, comunidades e ecossistemas no mundo; como por exemplo, o Brasil, estão expostos aos danos destas sustâncias que envenenam e são precursoras da morte. Esse artigo tem como objetivo realizar uma revisão dos estudos dos mecanismos celulares e algoritmos de como os agrotóxicos causaram problemas de saúde nos últimos 40 anos. A compreensão aprofundada do mecanismo de toxicidade sinérgica de pesticidas de múltiplos componentes, desempenha um papel importante no uso racional de pesticidas e na proteção da segurança alimentar.
\end{abstract}

Palavras chaves: Pesticidas; Mecanismos Celulares; Danos na Saúde.

\section{PESTICIDES BIOSCIENCE AND IT'S IMPACT ON HEALTH}

Abstract: It's a biomolecular and cellular approach, in the theme of the health damages produced by pesticides in Bioscience, as an interdisciplinary science, that studies the living beings, their evolution, the environment in which they live, the way they relate, etc. A state-of-the-art research has been carried out on articles published from 1979 to 2019. Since the 1960s, health impacts caused by pesticides have been studied and the population has been given package inserts with guidelines for the most appropriate forms of application of protective measures to be taken by farmers so that these health problems have a lesser impact on their well-being and consumers. Far from being fulfilled these protocols of prevention, entire families, communities and ecosystems in the world; Brazil, are exposed to the damages of these substances that poison and are precursors of death. This article has the general objective of reviewing the studies of the cellular mechanisms and algorithms of how pesticides cause health problems in the last 40 years, in the review of updated scientific researches. In-depth understanding of the synergistic toxicity mechanism of multi-component pesticides plays an important role in the rational use of pesticides and the protection of food safety.

Keywords: Pesticides, Cellular Mechanisms, Damage to Health. 


\section{LA BIOCIENCIA DE LOS AGROTÓXICOS Y SU IMPACTO EN LA SALUD}

Resumen: Se trata de un enfoque biomolecular y celular, en el tema de los perjuicios en la salud producidos por los agrotóxicos en la Biociencia, como ciencia interdisciplinaria, que estudia los seres vivos, su evolución, el ambiente en que viven, el modo en que se relacionan, etc. Se realizó una investigación de carácter cognoscitivo, del estado del arte, en artículos publicados de 1979 a 2019. Desde los años 60 que se estudia los impactos en la salud causados por los agrotóxicos y se suministran bulas a poblaciones, con orientaciones de las formas más adecuadas de la aplicación de medidas de protección a ser cumplidas por los agricultores, para que esos agravios a la salud tengan un menor impacto, en el estado de bienestar de ellos y de los consumidores. Lejos de que se cumplen estos protocolos de prevención, familias enteras, comunidades y ecosistemas en el mundo; por ejemplo, Brasil, están expuestos al daño de estas sustancias que envenenan y son precursoras de la muerte. Este artículo tiene como objetivo general realizar una revisión de los estudios de los mecanismos celulares y algoritmos de cómo los agrotóxicos causan problemas de salud en los últimos 40 años, en la revisión de investigaciones científicas actualizadas hasta entonces. La comprensión en profundidad del mecanismo de toxicidad sinérgica de plaguicidas de múltiples componentes, desempeña un papel importante en el uso racional de los plaguicidas y en la protección de la seguridad alimentaria.

Palabras claves: Pesticidas; Mecanismos Celulares; Daños en la Salud.

\section{INTRODUÇÃO}

Segundo o dicionário da "Cambridge", a Biociência é a ciência interdisciplinar que estuda os seres vivos, sua evolução, os ambientes em que vivem, o modo como se relacionam, etc. As companhias internacionais usam esta ciência para solucionar problemas em três mercados principais: na alimentação agrícola, nos bens de consumo e no controle de poluição. No caso da biociência dos agrotóxicos na ação do meio ambiental da saúde trata-se do estudo dos processos a níveis celulares que os agrotóxicos ocasionam danos.

A Revolução Verde foi à iniciativa de desenvolvimento das transferências de tecnologias entre os anos 1930 e o final da década de 1960 que aumentaram a produção agrícola em todo o mundo, particularmente no mundo em desenvolvimento, introduzindo os agrotóxicos como remédio ao combater as pragas nos cultivos. No ano 2008 o Brasil recebeu o título de maior consumidor de agrotóxicos, permanecendo até hoje com esse título. Isso está relacionado com a atual política agrícola do país, no qual o agronegócio está em expansão desde a década de 60. Esse modelo de produção de alimentos utiliza grandes quantidades de veneno em espaços concentrados de terra para propiciar a produção em larga escala (Silva, 2016).

Os impactos do uso inadequado de pesticidas no meio ambiente e na saúde pública em países em desenvolvimento e países em transição são bem conhecidos. O Registro Internacional de Produtos Químicos Potencialmente Tóxicos e o programa de Consentimento Livre, Prévio e Informado da Organização das Nações Unidas para Agricultura e Alimentação, são os primeiros passos para relatar os abusos e usos inadequados de produtos químicos agrícolas que poluem o ar e o solo causando sérios problemas em muitos países da América Latina, Ásia e Europa Oriental (Galindo e Alegria et al., 2018). 
Existe a presença de pesticidas nos ecossistemas costeiros de Sinaloa (México), que são os receptores finais de agroquímicos usados em vales agrícolas. Galindo et al. (1992) relataram a presença de metoxicloro, Y-hexaclorociclohexano (lindano), diclorodifenil-tricloroetano (DDT), endosulfan, dieldrina, clordanos e outros pesticidas na água, sedimentos e camarões do estuário do Teacapan localizado no sul de Sinaloa. Outro relatório (Galindo et al., 1997) documentou níveis de lindano, aldrin, DDT, heptacloro, dieldrin e paration metílico na água e sedimentos da lagoa Huizache Caimanero, um dos corpos de água costeira mais produtivos do sul de Sinaloa.

Em países como a Índia e China o aumento da variedade de uso de fertilizantes e pesticidas de alto rendimento, também contribuiu com sérios problemas ambientais e de saúde pública. O problema ocorre quando o nitrogênio aplicado excede a capacidade das plantas em absorvê-lo, e esta quantidade depende do tipo de planta, solo e rochas presentes no solo, podendo variar bastante entre as regiões e os países. Esse excesso de nitrogênio não absorvido fica acumulado no solo e o agricultor fica exposto a uma maior concentração (Goulding, 2000).

Segundo Pavani (2016) os tipos de agrotóxico incluem: inseticidas (controle de insetos), fungicidas (controle de fungos), herbicidas (combate às plantas invasoras), fumigantes (combate às bactérias do solo), algicida (combate a algas), avicidas (combate a aves), nematicidas (combate aos nematoides), moluscicidas (combate aos moluscos), acaricidas (combate aos ácaros), além de reguladores de crescimento, desfolhantes (combate às folhas indesejadas) e dissecantes (Silva e Fay, 2004; Baird, 2006).

Os agrotóxicos são uma das mais importantes inovações da agricultura moderna, mas trazem problemas de segurança alimentar, ao mesmo tempo em que protege as plantas de doenças e insetos infectados (Weiss et al., 2004). O uso de pesticidas na China alcançou 1,71 milhões de toneladas de acordo com os dados do Ministério da Agricultura. Como foi relatada muitas vezes a maioria dos pesticidas tem toxicidade contra o sistema nervoso. Pesticidas como organofosforados (OPs), pesticidas organoclorados (OCPs) e outros, podem afetar severamente a função do sistema nervoso de animais e até mesmo danos estruturais (Amaroli et al., 2013; Lee et al., 2015).

Segundo Hendriks et al. (2019) o destino ambiental de pesticidas agrícolas pode ter um impacto direto e indireto na saúde humana e no meio ambiente. A exposição humana a níveis tóxicos de diclorodifeniltricloroetano (DDT) pode resultar em aborto espontâneo nas mulheres. $O$ carbamato e organofosfato no ambiente podem resultar em perda de biodiversidade, e há evidências de que pesticidas podem desempenhar um papel em condições neurodegenerativas como demência e doença de Parkinson, e espalhar a resistência de insetos que estão envolvidos na transmissão de doenças humanas, como malária e dengue. Nesse caso, os pesticidas agrícolas têm um impacto indireto na saúde humana, reduzindo a eficácia das intervenções baseadas em inseticidas (Hendriks et al., 2019). 
Estudo experimental da China (Wang, 2011) também avaliou níveis de acumulação de alguns agrotóxicos em amostras de tecido adiposo humano, utilizando amostras de pacientes que fizeram operação abdominal entre abril de 2008 e junho de 2009. Dois agrotóxicos, o DDT (Dicloro-Difenil-Tricloroetano) e o $\mathrm{HCH}$ (Hexaclorociclohexano), estavam com concentrações elevadas no tecido adiposo humano, isso estava diretamente relacionado com o tempo de atividade na agricultura e com a idade dos pacientes operados, ou seja, essa característica foi observada em paciente mais velhos e com maior tempo de atividade agrícola. Outra observação importante foi que a concentração de agrotóxicos no tecido adiposo estava associada à mortalidade por tumores malignos.

Mais recentemente, no México, após relatos sugerindo casos de intoxicação por pesticidas usados na agricultura, e doenças crônicas entre trabalhadores rurais e populações próximas a fazendas, foi realizada uma pesquisa com o objetivo de medir os níveis de pesticidas em solo, água e em trabalhadores rurais no vale Navolato de Sinaloa para determinar o impacto potencial desses produtos químicos na sua população (Galindo e Alegria et al., 2018).

Os impactos à saúde humana causados pelos agrotóxicos são estudados desde o começo de seu uso nos anos 60, e são fornecidas bulas (cartilhas que explicam os riscos e as normas do uso segundo cada um dos remédios e as pragas que combatem) às populações, com as formas mais adequadas de aplicação e as medidas de proteção a serem cumpridas pelos usuários, para que esses agravos tenham um impacto menor no estado de bem-estar tanto dos agricultores como dos consumidores. Longe de acontecer essas rotinas protetivas, famílias inteiras, comunidades e ecossistemas no mundo, como por exemplo o Brasil, estão expostos aos danos destas sustâncias que envenenam e conseguem ser precursoras da morte. O objetivo geral desse artigo de revisão é o estudo dos mecanismos celulares e algoritmos de como os agrotóxicos causam problemas de saúde.

\section{METODOLOGIA}

Realizou-se uma investigação de caráter cognoscitivo do estado da arte, em artigos publicados nos sites de periódicos e revistas científicas (SCIELO, GOOGLE ACADÊMICO, PLUBMEDI, SCOPUS e WEB OF SCIENCE) presentes no Portal de Periódicos da Capes, sobre os mecanismos de danos à saúde, a níveis celulares, provocados pelos agrotóxicos ou pesticidas depois da revolução verde no planeta, para esclarecer os avanços de novas descobertas na Biociência destes pesticidas e as morbimortalidades dos últimos quarenta anos (1979 a 2019).

Revisaram-se aproximadamente 100 artigos dos últimos 40 anos e desses foram escolhidos os que representaram uma maior evidência científica para o estudo dos processos morfofuncionais ou patofisiológicos com uso dos agrotóxicos para a produção de alimentos.

Foram usadas as palavras chaves em português e em inglês (Keywords): agrotóxicos (pesticides); danos na saúde (damage to health), mecanismos imunológicos (Mechanism of 
immunotoxicity); processos celulares (cellular processes), danos biológicos (biological damage); revolução verde (green revolution). Esses vocábulos se indexaram misturados cada um as suas línguas mães.

Os critérios de inclusão dos artigos foram aqueles que apresentaram uma pesquisa com metodologias que fossem possíveis de serem reproduzidas ou aplicáveis, além de apresentar como objetivo geral o interesse na explicação de processos a nível celular, regulatório, de sistemas de funcionamento animal, aplicáveis em humanos, demostrando cientificamente danos na saúde provocados pelos agrotóxicos. Os trabalhos que foram excluídos não constituíram o interesse no momento para concluir a pesquisa, mas apresentaram significativamente grande importância para o esclarecimento sobre o tema estudado no presente artigo.

\section{AGROTÓXICOS NO SISTEMA NEUROLÓGICO}

O uso extensivo de pesticidas organofosforados (OPs) para controle de pragas agrícolas está associado a um alto risco de graves problemas de saúde humana, como a neurotoxicidade, imunotoxicidade e genotoxicidade. Estudos epidemiológicos sugerem que as maiorias dos efeitos prejudiciais são devido à imunotoxicidade. Diferentes efeitos imunomoduladores em mamíferos após a exposição de pesticidas organofosforados têm sido estudados e constatados os mecanismos que relacionam os danos em diferentes tecidos celulares como, por exemplo, nos neurônios (Mitra, 2019).

No estudo de neurotoxicidade sobre a bifentrina (inseticida organoclorado) realizado por de Gammon et al. (2019), eles avaliaram em ratos e na estrutura e função dos canais de sódio dependentes de voltagem (VGSC) de humanos, os efeitos que mostraram semelhanças com os piretróides (outro inseticida família da permetrina). Estes pesticidas atuam sobre o sistema nervoso de vertebrados exercendo um efeito significativo sobre os canais de sódio e interagem com os receptores GABA (do neurotransmissor Gabapentina) nos filamentos nervosos. A bifentrina produziu tremores e convulsões crônicas em mães e filhotes de ratos, e reduziu ligeiramente a amplitude de resposta acústica aumentando a Tmax (prova auditiva nos ratos), provocando hipoacusia ou surdez. A modelagem molecular da bifentrina indica que o grupo da enzima o-Me pode ocupar um espaço semelhante ao grupo da $\boldsymbol{\alpha}$-CN da cipermetrina e fenpropatrina, isto demostra que outros praguicidas podem ocasionar esses danos.

Gupta et al. (2019) classificam os inseticidas como de origem química e biológica podendo ser utilizados na agricultura, horticultura, florestas, jardins, residências e escritórios. Eles também são usados para controlar vetores, como mosquitos e carrapatos, que estão envolvidos na disseminação de doenças humanas e animais. Os inseticidas constituem um grande número de classes químicas e exercem toxicidade em insetos e mamíferos não-alvo (incluindo humanos) e aviários através de diferentes mecanismos de ação. Em espécies não alvo, os inseticidas podem produzir desde pequenas dores até paralisia severa e morte. Os inseticidas podem se ligar a 
diferentes enzimas, receptores e outras proteínas, e os sítios de ligação e moléculas, juntamente com resíduos de inseticidas e seus metabólitos, podem ser usados como biomarcadores de exposição e efeitos. Biomarcadores de suscetibilidade desempenham papéis significativos na identificação de subpopulações altamente sensíveis a inseticidas. A detecção de uma exposição precoce aos inseticidas não só ajudará a evitar qualquer exposição adicional, mas também proporcionará a oportunidade de um tratamento (Gupta et al., 2019).

Os organofosforados (OPs) são ésteres do ácido fosfórico e tem uma ampla gama de aplicações agrícolas e setores domésticos há mais de cinco décadas. O mais usado OPs são clorpirifós, malathion, acefato, naled, dicrotofos, fosmet, forato, diazinon, dimetoato e azinfosmetilo (Diaz-Resendiz et al., 2015). Os organofosforados foram introduzidos como um substituto do organoclorado que estava prejudicando os animais nas lavouras, pela tendência de se acumular na cadeia alimentar que criaram efeitos adversos à saúde para os carnívoros de alto nível (Murphy et al., 1986). Os organofosforados são muito eficientes em destruir pragas agrícolas, mas ao mesmo tempo são altamente tóxicos para espécies animais não-alvo, desafiando a sobrevivência das espécies em causa. A toxicidade aguda de todos os pesticidas organofosforados ocorre através da inibição da enzima acetilcolinesterase (AChE) por fosforilação, resultando em acúmulo de acetilcolina nos nervos terminais (Diaz-Resendiz et al., 2015). Isto leva à subsequente ativação de receptores colinérgicos (muscarínicos e nicotínico) seguido por dano respiratório e eventual morte (Timofeeva et al., 2008).

A resposta da toxicidade dos OPs se expressa de formas diversas, interespécies. Pode ser devido às diferenças em seu metabolismo celular, nas atividades de linha de base da enzima alvo, eletrofisiologia mediada por receptores e eventos no segundo mensageiro (Veronesi et al., 1996). A biotransformação de todos os compostos OPs são catalisados por monoxigenases polimórficas da superfamília do citocromo p450 (tal como 3A4,1A2, 2B6, 2C19, 2D6) e A esterasas resultando na formação de compostos dialquil-fosforosos (DAP) (Buratti et al., 2003; Sogorb e Vilanova, 2002).

Na maioria, os metabólitos dos compostos de OPs têm vida meia in vivo mais longas do que seus compostos de origem (Vasilic et al., 1992), desse modo exercendo mais neurotoxicidade do que a molécula mãe. Além de seu efeito neurotóxico, os OPs também exercem imunotóxico (Kumar et al., 2015), genotóxico (Bolognesi, 2003) e efeito antigonadal em vertebrados, pois é um potente disruptor endócrino que provoca esterilidade (Maitra e Mitra, 2008).

As vias de geração de imunotoxicidade com efeitos imunomoduladores de diferentes OPs em mamíferos incluem as alterações no número de linfócitos, na função alterada de células imunes principais como neutrófilos, macrófagos, linfócitos $B$, linfócitos $T$, alteração nos complementos séricos e também na imunossupressão. Inibição da AChE por OPs leva a superestimulação receptor colinérgico devido ao acúmulo de ACh (acetilcolina) em sinapse imunológica que desencadeia inflamação respostas em macrófagos e aumenta o risco de 
infecção. Uma segunda via de imunotoxicidade induzida por OP pode ocorrer através da inibição da serina hidrolases, um componente vital do sistema imunológico, o que leva à diminuição da atividade de células linfocitárias NK (exterminadoras naturais ou células NK), células LAK (células assassina ativada por linfocina são glóbulo branco que foram estimulados a matar células tumorais) e CTLs (são células $T$ efetoras que reconhecem e matam as células-alvo que expressam antígenos peptídicos estranhos) (Gammon et al., 2019).

Os organofosforados podem promover apoptose das células imunes que pode ocorrer através de ativação de qualquer formação de poros mitocondriais ou através da via grande enzima-perforina. Outra via de imunotoxicidade induzida por OPs, é através da fosforilação e desfosforilação de proteínas intracelulares SOCS3 (o supressor da sinalização de citosinas 3 ) e STAT (transdutor de sinal e do ativador da família de proteínas de transcrição) que, em última instância leva à não proliferação das células T (Mitra, 2019).

O sistema imunológico é mais sensível a qualquer agente externo, como qualquer xenobiótico. Substâncias estranhas ao organismo, capazes de alterar o mecanismo funcional do sistema neuro-endócrino e também a toxicidade genética. Essas substâncias se dissolvem em gordura e formam depósitos tóxicos capazes de aumentar a inflamação do corpo, alterar funções endócrinas e liberar radicais livres. São representados pelos agrotóxicos, pesticidas, plásticos, metais pesados, etc. (Blanco, 2011).

Dados de estudos em animais e estudos de casos humanos sugerem que muitos pesticidas são imunomoduladores porque o metabolismo da xenobiótica e a integridade funcional do sistema imunológico estão interconectados (Germolec et al., 1997). As consequências podem incluir o aumento do sistema imunológico, como hipersensibilidade e autoimunidade, ou supressão imunológica, que podem aumentar a incidência de doenças infecciosas ou a transformação neoplásica. Consequências adicionais podem ocorrer através de mecanismos de interação e feedback associados ao sistema nervoso central e endócrino (Blakley et al., 1999; Stiller-Winkler et al., 1999).

Organofosfatos como outros pesticidas induzem estresse (Rahimi e Abdollahi, 2007) que podem resultar na ativação do eixo HPA (Hipotálamo-hipoficiario-adrenal) e no sistema nervoso autônomo simpático. Os glicocorticóides adrenais e o eixo HPA controlam a reação ao estresse e regulam as respostas imunes. Glicocorticóides da glândula adrenal são responsáveis pela imunossupressão e inflamação (Parrillo e Fauci, 1979).

Outro caminho estabelecido para a comunicação neuro-imune é o sistema nervoso autônomo (SNA), através do qual o sistema nervoso central (SNC) está diretamente conectado aos tecidos viscerais através dos nervos simpáticos e parassimpáticos. As fibras nervosas simpáticas estão em contato direto com as células $T$ na polpa branca do baço. Um estudo de efeito semelhante ao estresse após a exposição a um inibidor reversível da colinesterase em pacientes que levam à produção de cortisol por meio da estimulação colinérgica; o cortisol é 
responsável pelo efeito imunomodulador subsequente. Da discussão acima, não seria diferente sugerir que uma substância química neurotóxica tenha o potencial de induzir imunotoxicidade (Figura 1) (Galindo e Alegria et al., 2018).

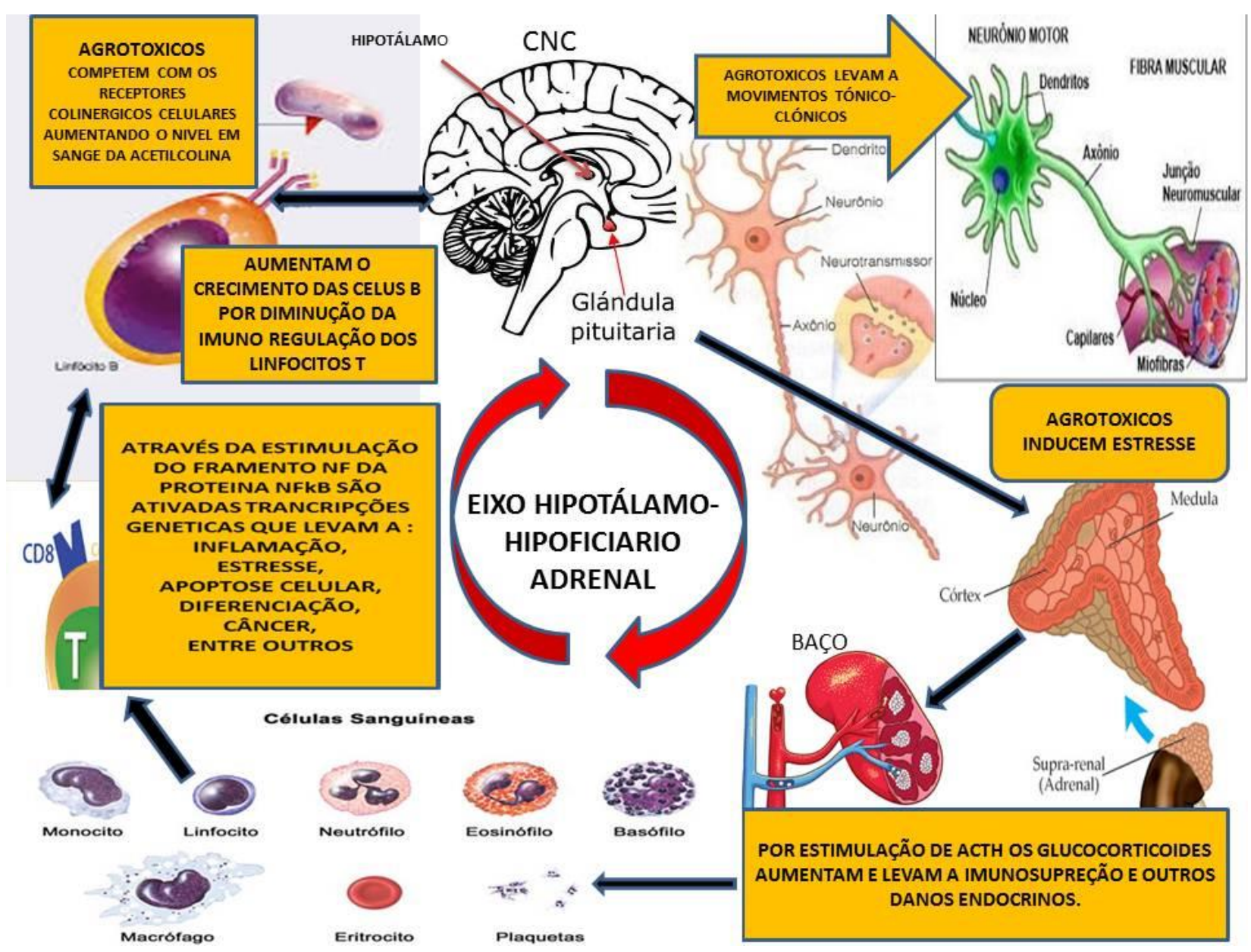

Figura 1. Processos desencadeados pelo uso de agrotóxico a nível celular no corpo humano. Fonte: Compilação adaptada pelo autor a partir de imagens do Google.

O sistema imunológico, o sistema nervoso central e autônomo interage através do eixo hipotalâmico-hipofisário-adrenal (HPA), compartilhando os mesmos receptores e moléculas de sinalização (Ader et al., 1991). Os sistemas neuroendócrino e imunológico são comunicados por meio de hormônios, citocinas e neurotransmissores por meio de várias vias (Blalock, 1994). O sistema imunológico e o eixo hipotálamo-hipófise-adrenal (eixo HPA) interagem através de um circuito que inclui: (1) ativação do HPAaxis e início da resposta ao estresse que possui propriedades imunomoduladoras; (2) um mecanismo de feedback derivado do sistema imunológico regulador Eixo HPA (Marx et al., 1998).

Organofosfatos como outros pesticidas induzem estresse (Rahimi e Abdollahi, 2007) que podem resultar na ativação do eixo HPA e no sistema nervoso autônomo simpático. Os glicocorticóides adrenais e o eixo HPA controlam a reação ao estresse e à regulação das respostas imunológicas. Os glicocorticoides da glândula adrenal são responsáveis pela 
imunossupressão e inflamação (Parrillo e Fauci, 1979). Outro caminho estabelecido para a comunicação neuro-imune é o sistema nervoso autônomo (SNA), através do qual o SNC está diretamente conectado aos tecidos viscerais por meio dos nervos simpáticos e parassimpáticos (Felten e Felten, 1994; Borovikova et al., 2000).

\section{IMUNOTOXICIDADE DOS ORGANOFOSFATOS EM ANIMAIS}

O sistema imunológico e o sistema neural formam uma complexa rede de proteção do hospedeiro do patógeno, bem como da inflamação interna (Tarkowski et al., 2004)

Segundo Mitra et al. (2019), os organofosforados são os pesticidas mais utilizados e induzem principalmente a toxicidade pela inibição de acetilcolinesterase (AChE) nas terminações nervosas do sistema nervoso central e periférico, levando a uma variedade de efeitos a curto prazo e crônicos nos animais não-alvos. Além da acetilcolinesterase, os OPs são conhecidos inibidores potentes de serina hidrolasas que são vitais componentes do sistema imunológico e, portanto, influenciam as funções imunológicas. Os organofosforados induzem vários efeitos imunomoduladores nos vertebrados alterando a função dos neutrófilos, produção de macrófagos, produção de anticorpos, imunossupressão, produção reduzida de interleucina e proliferação células $\mathrm{T}$.

A imunotoxicidade devido à exposição aos OPs é atrapalhada ao ser cancelada a resposta colinérgica de linfócitos, alterando a transdução de sinal, não acontecendo a via de exocitose dos grânulos de colinesterase e comprometendo a via FasL/Faz (vias de ativação de células com atividade imunológica) de células natural killer e outras respostas protetoras das células relacionadas com o sistema imunológico. Isto acontece estimulando a apoptose de linfócitos ou células imunes relacionadas e promovido através da formação de poros mitocondriais e fragmentação de DNA (Mitra, 2019).

\section{APOPTOSE CELULAR POR ESTIMULAÇÃO AGROTÓXICA}

Em estudo na China sobre avaliação do risco de resíduos de pesticidas, descobriram que os mecanismos de toxicidade sinérgica dos pesticidas podem regular a apoptose e as proteínas relacionadas ao ciclo celular, e o efeito depende da geração de resíduos dos pesticidas (Fu et al., 2019).

A apoptose é uma forma de morte celular programada, ou "suicídio celular". É diferente de necrose, na qual as células morrem por causa de uma lesão. A apoptose é um processo ordenado, no qual o conteúdo da célula é compactado em pequenos pacotes de membrana para a "coleta de lixo" pelas células do sistema imunológico (Chauffaille, 2005).

O 5 organofosfato (OP) induz apoptose em linfócitos ou a oligomerização imunológica, que é uma apoptose induzida por ativação mitocondrial. Os organofosforados induzem ao Bax/Bak que são duas proteínas nucleares codificadas que estão presentes em eucariotos superiores 
capazes de perfurar a membrana externa mitocondrial para mediar a morte celular por apoptose, na membrana interna mitocondrial desencadeando a liberação de citocromo c, que se agrupa com um anticorpo Apaf-1 e a cascata enzimática 9; levando à formação do apoptossoma. 0 Apoptosome finalmente ativa a cascata 3 , que leva à morte celular programada. A apoptose induzida por ativação de perforina (via da Grande-enzima B) é responsável pela fragmentação do DNA, através da ativação do complexo SET (NM23-H1) que também leva à ativação de cascata 3 terminando todas em morte celular (Mitra, 2019).

\section{ESTRESSE OXIDATIVO CELULAR NO USO DE PESTICIDAS}

Processos ou proteínas da respiração neuronal da célula regulam positivamente as espécies reativas de oxigênio (ERO), desenvolvem o estresse oxidativo (EO) e danificam as células. $O$ aumento de espécies reativas de oxigênio é um importante indicador da ocorrência de estresse oxidativo, o que pode levar ao desequilíbrio redox, que geralmente tem efeito negativo sobre células, tecidos e organismos (Dan Dunn et al., 2015; Hayashi e Cortopassi, 2015; Sies, 2015).

É bem conhecido que as ERO podem regular positivamente as proteínas pró-apoptose, como as cascatas da protease aspárticas da cisteína, aspartases da cisteína ou proteases dirigidas ao aspartato dependentes da cisteína. As caspases são uma família de enzimas proteases que desempenham papéis essenciais na morte celular programada (incluindo apoptose, piroptose, necroptose e inflamação). Regulam para baixo as proteínas anti-apoptose, como Bcl-2. Então induzirá a apoptose (Zhang et al., 2016; Cheng et al., 2018). Outras evidências mostraram que as ERO podem induzir a interrupção do ciclo celular por influenciar as proteínas relacionadas (Puente et al., 2014; Agarwal et al., 2018).

De modo que a geração de ERO irá danificar as células, tecidos e organismos, e inibir a proliferação como resultado. A toxicidade sinérgica trará riscos significativos para a segurança alimentar. Quando qualquer indicador nutricional estiver em risco, a toxicidade sinérgica pode causar a perda de novos organismos (Chen et al., 2015; Wang et al., 2018). A compreensão aprofundada e abrangente do mecanismo de toxicidade sinérgica de pesticidas de múltiplos componentes desempenha um papel importante no uso racional de pesticidas e na proteção da segurança alimentar (Fu et al., 2019).

Estresse oxidativo gerado após exposição aos OPs altera a atividade de enzimas antioxidantes, resultando em produção excessiva de óxido nítrico e/ou aumento da peroxidação lipídica em humanos e animais. Uma produção excessiva de espécies reativas de oxigênio pode desempenhar um papel crucial na intoxicação induzida por OPs. (Gupta et al., 2001; Monteiro et al., 2006).

Outra via possível de imunotoxicidade por indução de OPs pode ser através da ativação do eixo hipotálamo hipofisiario adrenal (HPA), que com exposição aos OPs induz estresse no sistema 
nervoso central (SNC). A liberação de glicocorticoides da glândula adrenal, devido à ativação do eixo HPA é responsável pela imunossupressão e inflamação. Assim, múltiplos alvos e mecanismos existem acionados para gerar imunotoxicidade pelo grande e complexo que é este eixo. Poucos mecanismos têm sido explorados para alguns organofosfatos (exemplo as permetrinas). Para uma melhor compreensão é necessário pesquisas futuras dessas interações (Mitra, 2019).

\section{DIFERENTES TIPOS DE CÂNCER SÃO INDUZIDOS PELOS AGROTÓXICOS}

Entre 80 a 90\% dos cânceres que são registrados no mundo estão associados a fatores ambientais (Guerra et al., 2005). Na Conferência das Nações Unidas sobre Comércio e Desenvolvimento (United Nations Conference on Trade and Development) de 2013 tratou-se entre outros aspectos, o tema das substâncias ativas com alto grau de toxicidade aguda comprovada (pesticidas e outras), que causam problemas neurológicos, reprodutivos, desregulação hormonal e câncer. Discutiram-se que os efeitos carcinogênicos do fator ambiental "consumo crônico de agrotóxicos", estão associados à alimentação (ANVISA, 2010).

É grande o número de pesquisas que mostraram a inflamação crônica como predisposição em indivíduos que têm vários tipos de câncer (Mantovani, 2008; Costa et al., 2017; Fu et al., 2019; Mitra, 2019; Oliveira, 2019). Como muitos organofosforados (agrotóxicos) são amplamente utilizados na agricultura, uma tentativa de reduzir o nível de resíduos desse produto químico e a prevenção da exposição prolongada deve ser uma prioridade importante para o ser humano devido ao potencial de problemas crônicos de saúde, como danos aos órgãos, efeitos neurológicos e câncer (Costa et al., 2017).

O NFkB é uma proteína citosólica que, em sua forma inativa, está ligada covalentemente ao inibidor de $\mathrm{kB}(\mathrm{lkB})$. Quando o NFkB é ativado, ele se dissocia do $\mathrm{lkB}$ e é translocado para o núcleo da célula (Ranjan e Baltimore, 1986). Segundo Baldwin Junior (2001), a ativação de NFkB está relacionada à vários tipos de doenças encontradas em humanos como: asma, inflamação colorretal e AIDS. Além disso, tem um papel central na regulação da transcrição de genes relacionados ao câncer, promovendo a síntese de citocinas pró-inflamatórias, proteínas antiapoptóticas e reguladores de ciclo celular (Oliveira, 2019).

A ativação do NFKB realizada pelas citocinas pró-inflamatórias como TNFa (Fatores de Necrose Tumoral Alfa), Interleucina 1 (II-1) e pelos receptores do tipo Toll-like é conhecida como via canônica ou clássica. Na via canônica, a ativação do NFkB é controlada pelo complexo IkB quinase (IKK), composto pelas subunidades IKKa e IKKß e uma subunidade regulatória IKKY também conhecida como NEMO (modulador essencial de NFKB) (Israël, 2010).

O complexo IKK é ativado por proteínas da família das MAP quinases, em uma cascata de reações, cuja função é fosforilar as subunidades IKKa e IKKß com propriedades catalíticas (Mitra et al, 2019). Devido à alta afinidade pelo $I K B$, IKKa e IKK $\beta$ fosforilam o IKB resultando na 
ubiquitinação do mesmo e posterior degradação pelo proteassoma 26s. Livre de seu inibidor, o NFkB é translocado para o núcleo onde realizará a transcrição de genes específicos (Karin e Greten, 2005).

O NFKB normalmente é regulado pelo mecanismo de retroalimentação negativa, pois tem a capacidade de transcrever o gene para produção de $\mathrm{kkB}$, mas em doenças como o adenocarcinoma prostático humano foi relatada a ativação constante do fator, o que está relacionado com a progressão tumoral (Shukla et al., 2004).

A ativação de NFKB mediada por TNFa exibe dois padrões de resposta: a primeira é de curta duração, caracterizada por intensa regulação por retroalimentação negativa, que logo inativa o NFKB; a segunda é caracterizada por longa exposição à TNFa, causando um padrão oscilatório de ativação e inativação de NFKB, mediada pela transcrição e destruição de IkB. Alguns genesalvo do processo de carcinogênese só são transcritos na fase oscilatória (Alberts et al., 2017).

Nguyen et al. (2014) mostraram que a ativação de NFkB tem sido reconhecida como o maior efetor de processos pró-inflamatórios, bem como da patogênese na próstata. As citocinas inflamatórias favorecem a formação de complexos de NFkB para sinalização anti-apoptótica em células do câncer de próstata. A via de sinalização do NFKB desempenha papel importante nas respostas ao câncer, inflamação e estresse (Pahl, 1999), além de participar de processos celulares fundamentais, como a apoptose, proliferação e diferenciação (Pham et al., 2004; Luo et al., 2005).

O Linfoma não Hodgkin (LNH) é composto por 40 subtipos histológicos oriundos do sistema linfático, e seus mecanismos de formação incluem alterações nos processos de imunorregulação, principalmente dos linfócitos $\mathrm{T}$, resultando em diminuição das citosinas responsáveis pela resposta imune e pelo aumento do crescimento das células $B$ no tecido linfoide (Greer et al., 2009; Costa et al., 2017).

$\mathrm{Na}$ Itália um estudo ecológico de "Diagnósticos de câncer entre a população da província de Vercelli", foram considerados todos os novos casos registrados de câncer entre a população durante o período de quatro anos, dividindo os casos entre agricultores e não agricultores. Os agricultores apresentaram um maior risco para o desenvolvimento de tumores: colorretal, sistema digestivo, linfoma, melanoma, mieloma, pâncreas, pulmão e rim, em comparação com os não agricultores (Salerno et al., 2014).

Estudos relacionados à carcinogênese, por consumo de alimentos com agrotóxicos, vinculam-se a neoplasias do sistema imunológico, reprodutor masculino, sistema digestório, sistema urinário, sistema respiratório e sistema endócrino (Costa et al., 2017).

\section{ORGANOFOSFORADOS SÃO DESREGULADORES ENDÓCRINOS}

Segundo Oliveira (2019), praguicida organofosforados são desreguladores endócrinos (DE). Os DEs abrangem uma grande faixa de classe de substâncias, incluindo substâncias 
naturais e substâncias sintéticas, como as utilizadas na agricultura, e hormônios sintéticos e naturais, como compostos farmacêuticos (17a-etinilestradiol) e estrógenos naturais (17ß-estradiol) (Bila e Dezotti, 2007).

Os DEs podem perturbar o eixo hipotálamo-hipófise-testículo afetando o sistema endócrino e as funções reprodutivas. Além da redução, da fertilidade e da disfunção erétil, desenvolvimento sexual anormal, alteração nas funções da hipófise e da glândula tireoide, supressão imunológica e efeitos neurocomportamentais. Os DEs podem causar câncer de testículo e de próstata (Sikka e Wang, 2008; Schug et al., 17 2011), bem como induzir alterações reprodutivas, obesidade, alterações comportamentais e inflamação (Soto e Sonnenschein, 2010).

Uma das principais limitações assinaladas para a determinação do fator causal é a dificuldade de identificação das sustâncias ativas nas amostras clínicas. Essa dificuldade pode ser por fatores como metodologias analíticas disponíveis nas redes de laboratórios, diversidade de metabólitos e aspectos toxicocinéticos, como meia-vida curta, que resulta na rápida eliminação do agente (Alavanja et al., 2014).

\section{CONSIDERAÇÕES FINAIS}

O uso extensivo de pesticidas organofosforados (OPs) para controle de pragas agrícolas está associado a um alto risco de graves problemas de saúde humana, como a neurotoxicidade, imunotoxicidade e genotoxicidade. Sendo a imunotoxicidade o centro dos efeitos prejudiciais e a toxicidade mais comprometida no organismo.

A bifentrina ou qualquer outra permetrina, como outros inseticidas atuam sobre o sistema nervoso provocando convulsões e descargas sinápticas ativando também, mecanismos neuroendócrinos no arco ou eixo hipotálamo hipoficiario adrenal.

Diferentes efeitos imunomoduladores em mamíferos e humanos após a exposição com pesticidas organofosforados têm sido demostrados, que levam na maioria dos processos biológicos, à morte celular. Uma dessas mortes (a Apoptose) das células imunes pode ocorrer através da ativação de qualquer formação de poros mitocondriais ou através da via perforinagrande-enzima. Os efeitos imunomoduladores de diferentes OPs em mamíferos incluem a alteração nos números linfócitos, função alterada de células imunes principais como neutrófilos, macrófagos, linfócitos $B$, linfócitos $T$, alteração nos complementos séricos e também na imunossupressão.

A inibição da enzima acetilcolinesterase (AChE) por OPs leva à super estimulação do receptor colinérgico devido ao acúmulo de acetilcolina (ACh) em sinapse imunológica que desencadeia inflamação respostas em macrófagos e aumenta o risco de infecção.

Uma segunda via de imunotoxicidade induzida por OPs pode ocorrer através da inibição das serina-hidrolasas, um componente vital do sistema imunológico, o que leva à diminuição da atividade de células NK, células LAK e CTLs. Outra via estabelecida de imunotoxicidade induzida 
por OPs é através da fosforilação e desfosforilação de proteínas intracelulares SOCS3 e STAT, o que conduz à proliferação de células T bloqueadas.

Os fatores da inflamação ativados pelos agrotóxicos vão levar ao mecanismo de separação molecular, com a ativação de uma cascata pelo modulador NEMO dentro da célula, para entrar no núcleo e ativar a transcrição de genes que levam a modificar as células a células cancerígenas, e além disso ativar outros processos também inflamatórios como a ASMA, apoptoses, esterilidade, diferenciação celular entre outros fatores ainda em estudos.

Os agrotóxicos longe de serem remédios para melhorar a vida das populações no desenvolvimento agrícola se convertem na morte silenciosa dos ecossistemas e seres humanos.

\section{REFERÊNCIAS}

Ader, R.; Felten D. L.; N. Cohen (eds.) Psychoneuroimmunology, 2nd ed. San diego: Academic Press, 1991.

Agarwal, A.; Kasinathan, A; Ganesan, R.; Balasubramanian, D.; Bhaskaran, J.; Suresh, S.; Srinivas, R.; Aravind, K. V.; Sivalingam, N. Curcumin induces apoptosis and cell cycle arrest via the activation of reactive oxygen species-independent mitochondrial apoptotic pathway in Smad4 and p53 mutated colon adenocarcinoma HT29 cells. Nutriton Research, 51, 67-81, 2018.

Agência Nacional de Vigilância Sanitária. Relatório Final do Programa de Analise de Resíduos de Agrotóxicos em Alimentos (PARA) ANVISA, 2010.

Alavanja, M. C.; Hofmann, J. N.; Lynch, C. F.; Hines, C. J.; Barry, K. H.; Barker, J.; Buckman, D. W.; Thomas, K.; Sandler, D.P.; Hoppin, J. A.; Koutros, S.; Andreotti, G.; Lubin, J. H.; Blair, A.; Beane Freeman, L. E. Non-hodgkin lymphoma risk and insecticide, fungicide and fumigant use in the agricultural health study. PLoS One, 9(10), 800-814, 2014.

Alberts, B. Biologia Molecular da Célula. 6aㅗ ed. Porto Alegre: Artmed, 2017.

Amaroli, A; Aluigi, M. G; Falugi, C; Chessa, M. G. Effects of the neurotoxic thionophosphate pesticide chlorpyrifos on differentiating alternative models. Chemosphere, 90(7), 2115-2122, 2013.

Baird, C. Chemistry in your life. 2. ed. New York: W. H. Freeman, 2006.

Baldwin Jr., A. The transcription factor NF-KB and human disease. The Journal Clinical Investigation, 107(1), 1-5, 2001.

Bila, D. M.; Dezotti, M. Desreguladores endócrinos no meio ambiente: efeitos e consequências. Quimica. Nova, 30(3), 651-666, 2007.

Blakley, B. R.; Yole, M. J; Brousseau, P; Boermans, H; Fournier, M. Effect of chlorpyrifos on immune function in rats. Veterinary and Human Toxicology 41(3), 140-144, 1999.

Blalock, J. E. The syntax of immune-neuroendocrine communication. Immunology Today, 15, 504-511, 1994.

Blanco, G. A. Immune response to environmental exposure. Elsevier. 2011.

Bolognesi, C. Genotoxicity of pesticides: A review of human biomonitoring studies. Mutation Research/Reviews in Mutation Research, 543(3), 251-272, 2003. 
Borovikova, L. V.; Ivanova, S.; Zhang, S.; Yang, H.; Botchkina, G. I.; Watkins, L. R.; Wang, H.; Abumrad, N.; Eaton, J. W.; Tracey, K. J. Vagus nerve stimulation attenuates the systemic inflammatory response to endotoxin. Nature 405, 458-562, 2000.

Buratti, F. M.; Volpe, M. T.; Meneguz, A.; Vittozzi, L.; Testai, L. CYP-specific bioactivation of four organophosphorothionate pesticides by human liver microsomes. Toxicology and Applied Pharmacology, 86, 143-154, 2003.

Chauffaille, M. L. L. F. A propósito da apoptose em LMC: estudos promissores. Rev. Bras. Hematol. Hemoter. São José do Rio Preto, 27(2), 81-82, 2005.

Chen, C.; Wang, Y.; Qian, Y.; Zhao, X.; Wang, Q. The synergistic toxicity of the multiple chemical mixtures: implications for risk assessment in the terrestrial environment. Environment International, 77, 95-105, 2015.

Cheng, K.; Sano, M.; Jenkins, C. H.; Zhang, G.; Vernekohl, D.; Zhao, W.; Wei, C.; Zhang, Y,; Zhang, Z.; Liu, Y.; Cheng, Z.; Xing, L. Synergistically enhancing therapeutic effect of radiation therapy with radiation activatable and reactive oxygen species-releasing nanostructures. ACS Nano, 99(2), 4496-4958, 2017.

Costa, V. I. B; Sarpa, M.; Friedrich, K. Environmental and occupational exposure to pesticides and the non- Hodgkin lymphoma. Saúde Debate | Rio de Janeiro, 41(112), 49-62, 2017.

Dan Dunn, J.; Alvarez, L. A.; Zhang, X.; Soldati, T. Reactive oxygen species and mitochondria: a nexus of cellular homeostasis. Redox Biology, 6, 472-485, 2015.

Dıaz-Resendiz, K. J. G.; Toledo-Ibarra, G. A.; Girón-Pérez, M. I. Modulation of immune response by organophosphorus pesticides: Fishes as a potential model in immunotoxicology. Journal of Immunology Research, 2015, 1-10, 2015.

Felten, S. Y.; Felten, D. L. Neural-immune interactions. Progress in Brain Research, 100, 157-162, 1994.

Fu, D. J.; Li, P.; Song, J.; Zhang, S. Y.; Xie, H. Z. Mechanisms of synergistic neurotoxicity induced by two high risk pesticide residues - Chlorpyrifos and Carbofuran via oxidative stress. Toxicology in Vitro, 54, 338-344, 2019.

Galindo RJ, Medina JM, Villagrana LC, Ibarra CL. Condições ambientais e de poluição da lagoa Huizache-Caimanero, no noroeste do México. Boletim de Poluição Marinha. 1 de dezembro; 34 (12): 1072-7, 1997.

Galindo, J. G. R; Alegria, H. Toxic Effects of Exposure to Pesticides in Farm Workers in Navolato, Sinaloa (MEXICO). Revista Contaminación Ambiental, 34(3), 505-516, 2018.

Galindo-Leal C. Overestimation of deer densities in Michilia Biosphere Reserve, Durango, Mexico. The Southwestern Naturalist. Jun 1;37(2):209-12.,1992.

Gammon, D. W.; Liu, Z.; Chandrasekaran, A.; Shaaban, F.; El-Naggar.; Kuryshev, Y. A.; Jackson, S. Pyrethroid neurotoxicity studies with bifenthrin indicate a mixed Type I/II mode of action. Published online in Wiley Online Library, 75(4), 1190-1197, 2019.

Germolec, D.R, Spalding, J., Boorman, G.A, Wilmer, J.L, Yoshida, T., Simeonova, P.P \& Burleson, F. O arsênico pode mediar a neoplasia da pele por estimulação crônica de fatores de crescimento derivados de queratinócitos. Mutation Research/Reviews in Mutation Research. 386(3), 209-218, 1997.

Goulding, K. Nitrate leaching from arable and horticultural land. Soil use and management, 16,145$151,2000$. 
Greer, J. P.; Reddy, N. M.; Willians, M. E. Non- Hodgkin Lymphoma in Adults. Wintrobe's clinical hematology, 41(112), 1827-1837, 2009.

Guerra, M. R.; Gallo, C. V. M.; Mendonça, G. A. S. Risco de câncer no Brasil: tendências e estudos epidemiológicos mais recentes. Revista Brasileira de Cancerologia, 51(3), 227-234, 2005.

Gupta, R. C; Miller, I. R. M; Malik, J. K; Doss, R. B; Dettbam, W. D; Milatovic, D. Insecticides. Livro Biomarker in toxicologia. Chapter 20. Second edition. Elsevier, p.455-475, 2019.

Hayashi, G; Cortopassi, G. Oxidative stress in inherited mitochondrial diseases. Free Radical Biology and Medicina, 88(A), 10-17, 2015.

Hendriks, C; Gibson, H.; Trett, A.; Python, A.; Weiss, D.; Vrieling, A.; Moyes, C. Mapping geospatial processes affecting the environmental fate of agricultural pesticides in Africa. EarthArXiv, 2019. Disponível em: https://doi.org/10.31223/osf.io/db2qz. Acesso em: 30 de maio 2019.

Israël A. The IKK complex, a central regulator of NF-kappaB activation. Cold Spring Harb Perspect Biol, 2(3), a000158, 2010.

Karin, M.; Greten, F. NF-kB: Linking inflammation and immunity to cancer development and progression. Nature, 5(1), 749-759, 2005.

Kumar, A.; Bhaskar, A.; Chandra, S.; Sasmal, D.; Mukhopadhyay, K. M.; Sharma, N. Mechanism of deltamethrin induced immunotoxicity: Current and future perspectives. Receptors and Clinical Investigation, 2(2), 1-7, 2015.

Lee, I.; Eriksson, P.; Fredriksson, A.; Buratovic, S.; Viberg, H. Developmental neurotoxic effects of two pesticides: behavior and neuroprotein studies on endosulfan and cypermethrin Toxicology, 335, 1-10, 2015.

Luo, J. L.; Kamata, H.; Karin, M. IKK/NF-kappaB signaling: balancing life and death - a new approach to cancer therapy. The Journal of Clinical investigation, 115, 2625-2632, 2005.

Maitra, S. K. A.; Mitra, A. Testicular functions and serum titers of $\mathrm{LH}$ and testosterone in methyl parathion-fed roseringed parakeets. Ecotoxicology and Environmental Safety, 71(1), 236-244, 2008.

Mantovani, A.; Allavena, P.; Sica, A. Cancer-related inflammation. Nature, 454(24), 436-444, 2008.

Marx, C.; Ehrhart-Bornstein, M.; Scherbaum, W. A.; Bornstein, S. R. Regulation of adrenocortical function by cytokines-relevance for immune-endocrine interaction. Hormone and Metabolic Research, 30(67), 16-20, 1998.

Mitra, A.; Sarkar, M.; Chatterjee, C. Modulation of Immune Response by Organophosphate Pesticides: Mammals as Potential Model. Revista: Proc Zool Soc, 72(1), 13-24, 2019.

Murphy, E. C.; Springer, A. M.; Roseneau, D. G. Population status of Common Guillemots Uriaaalge at a colony in western Alaska: Results and simulations. Ibis International Journal of Avian Science, 128(3), 348-363, 1986.

Nguyen, D. P.; Li, J.; Yadav, S. S.; Tewari, A. K. Recent insights into NF-KB signalling pathways and the link between inflammation and prostate cancer. BJU International, 114(2), 168-176, 2014.

Oliveira, F. S. Influência do praguicida diclorvós sobre o desenvolvimento de lesões prostáticas induzidas por MNU em ratos - avaliação de marcadores moleculares de inflamação. p 14-37, 2019.

Disponível

em: 
https://repositorio.unesp.br/bitstream/handle/11449/181983/santos_fo_me_assis_par.pdf?sequenc $\mathrm{e}=11$ \&isAllowed=y. Acesso em: 30 de maio 2019.

Pahl, H. L. Activators and target genes of Rel/NF-kappaB transcription factors. Oncogene, 18, 6853-6866, 1999.

Parrillo, J. E.; Fauci, A. S. Mechanisms of glucocorticoid action on immune processes. Annual Review 19(1), 29-201, 1979.

Pavani, N. D. Pesticidas: uma revisão dos aspectos que envolvem esses compostos. 2016. Trabalho de Conclusão de Curso (licenciatura - Química) - Universidade Estadual Paulista, Faculdade de Ciências, 2016. Disponível em: http://hdl.handle.net/11449/136596. Acesso em: 25 de maio de 2019.

Pham, C. G.; Bubici, C.; Zazzeroni, F.; Papa, S.; Jones, J.; Alvarez K. Ferritin heavy chain upregulation by NF-kappaB inhibits TNFalphainduced apoptosis by suppressing reactive oxygen species. Cell, 119(4), 529-542, 2004.

Puente, B. N.; Kimura, W.; Muralidhar, S. A.; Moon, J.; Amatruda, J. F.; Phelps, K. L.; Grinsfelder, D.; Rothermel, B. A.; Chen, R.; Garcia, J. A.; Santos, S. Thet, E. Mori, M. T. Kinter, P. M. Rindler, S. Zacchigna, Mukherjee; D. J. Chen; A. I. Mahmoud; M. Giacca; P. S. Rabinovitch; A. Aroumougame; A. M. Shah; L. I. Szweda; H. A. Sadek. The oxygen-rich postnatal environment induces cardiomyocyte cell-cycle arrest through DNA damage response. Cell, 157 (3), 565-579, 2014.

Rahimi, R.; Abdollahi, M. A review on the mechanisms involved in hyperglycemia induced by organophosphorus pesticides. Pesticide Biochemistry and Physiology, 88(2): 115-121, 2007.

Ranjan, S.; Baltimore, D. Inducibility of K Immunoglobulin Enhancer-Binding Protein NFKB by a Posttranslational Mechanism. Cell, 47, 921-926, 1986.

Rubin, R. T.; O'Toole, S. M.; Rhodes, M. E.; Sekula, L.K.; Czambel, R.K. Hypothalamo-pituitaryadrenal cortical responses to low-dose physostigmine and arginine vasopressin administration: Sex differences between major depressives andmatched control subjects. Psychiatry Research, 89, 1-20, 1999.

Salerno, C.; Sacco, S; Panella, M.; Berchialla, P.; Vanhaecht, K.; Palin, L. A. Cancer risk among farmers in the Province of Vercelli (Italy) from 2002 to 2005: an ecological study. Annali di igiene: medicina preventiva e di comunità, 26(3), 255-263, 2014.

Schug, T. T.; Janesick, A.; Blumberg, B.; Heindel, J. J. Endocrine disrupting chemicals and disease susceptibility. J. Steroid Biochem, 127, 204-215, 2011.

Shukla, S.; MacLennan, G. T.; Fu, P.; Patel, J.; Marengo, S. R.; Resnick, M. I.; Gupta, S. Nuclear factor-kB/p65 ( Rel A) is constitutively activated in human prostate adenocarcinoma and correlates with disease progression. Neoplasia, 6(4), 390-400, 2004.

Sies, H. Oxidative stress: a concept in redox biology and medicine. Redox Biol, 4,180-183, 2015.

Sikka, S. C.; Wang, R. Endocrine disruptors and estrogenic effects on male reproductive axis. Asian Journal of Andrology, 10(1),134-145, 2008.

Silva, C. M. M.; Fay, E. F. Agrotóxicos e ambiente. Brasília: Embrapa Informação Tecnológica, 400,17-76, 2004.

Silva, L. S; Félix, M. R. M; Araújo, M. V. S; Perace, I. M. Revolução Verde: reflexões acerca da questão dos agrotóxicos. Revista Científica do Centro de Estudos em Desenvolvimento Sustentável da UNDB, 1(4), 1-24, 2016. 
Sogorb, M. A.; Vilanova, E. Enzymes involved in the detoxification of organophosphorus, carbamate and pyrethroid insecticides through hydrolysis. Toxicology Letters, 128(1), 215-228, 2002.

Soto, A.; Sonnenschein, C. Environmental causes of cancer: endocrine disruptors as carcinogens Nature Reviews Endocrinology, 6, 363-370, 2010.

Stiller-Winkler, R.; Hadnagy, W.; Leng, G.; Straube, E.; Idel, H. Immunological parameters in humans exposed to pesticides in the agricultural environment. Toxicology Letters, 107(1), 219224, 1999.

Tarnowski C.P, Ignelzi J.R MA, Wang W, Taboas J.M, Goldstein S.A, Morris M.D. Earliest mineral and matrix changes in force-induced musculoskeletal disease as revealed by Raman microspectroscopic imaging. Journal of Bone and Mineral Research. Jan;19(1), 64-71. 2004.

Timofeeva, O. A.; Roegge, C. S.; Seidler, F. J.; Slotkin, T. A.; Levin, E. D. Persistent cognitive alterations in rats after early postnatal exposure to low doses of the organophosphate pesticide, diazinon. Neurotoxicology and Teratology, 30(1), 38-45, 2008.

United Nations Conference on Trade and Development. Wake up before it is too late: Make agriculture truly sustainable now for food security in a changing climate. UNCTD, 2013. Disponível em: https://unctad.org/en/pages/PublicationWebflyer.aspx?publicationid=666. Acesso em: 20 de março 2019.

Vasilic, Z.; Drevenkar, V.; Rumenjak, B.; Stengl, B.; Frobe, Z. Urinary excretion of diethylphosphorus metabolites in persons poisoned by quinalphos or chlorpyrifos. Archives of Environmental Contamination and Toxicology, 22(4), 351-357,1992.

Veronesi, B. M.; Ehrich, J. K.; Blusztajn, M.; Ortgiesen, O.; Durham, H. Cell culture models of interspecies selectivity to organophosphorous insecticides. Neurotoxicology, 18(1), 283-297, 1996.

Wang, N.; Shi, L.; Kong, D.; Cai, D.; Cao, Y.; Liu, Y.; Pang, G.; Yu, R. Accumulation levels and characteristics of some pesticides in human adipose tissue samples from Southeast China. Chemosphere, 84(7), 964-971, 2011.

Wang, Y. S.; Wu, J.; Chen, C.; Zhang, Z.; Xu, G.; Li, L.; Cai, W.; Shen, Q. Wang Single and joint toxicity assessment of four currently used pesticides to zebrafish (Danio rerio) using traditional and molecular endpoints. Chemosphere, 192, 14-23, 2018.

Weiss, B; Amler, S; Amler, R. W. Pesticides. Pediatrics, 113(4), 1030-1036, 2004.

Zhang, S; T. Li, Y.; Zhang, H.; Xu, Y.; Li, X.; Zi, H.; Yu, J.; Li, C.Y.; Jin, H.M.; Liu, A. A new brominated chalcone derivative suppresses the growth of gastric cancer cells in vitro and in vivo involving ROS mediated up-regulation of DR5 and 4 expression and apoptosis. Toxicology and Applied Pharmacology, 309, 77-86, 2016. 